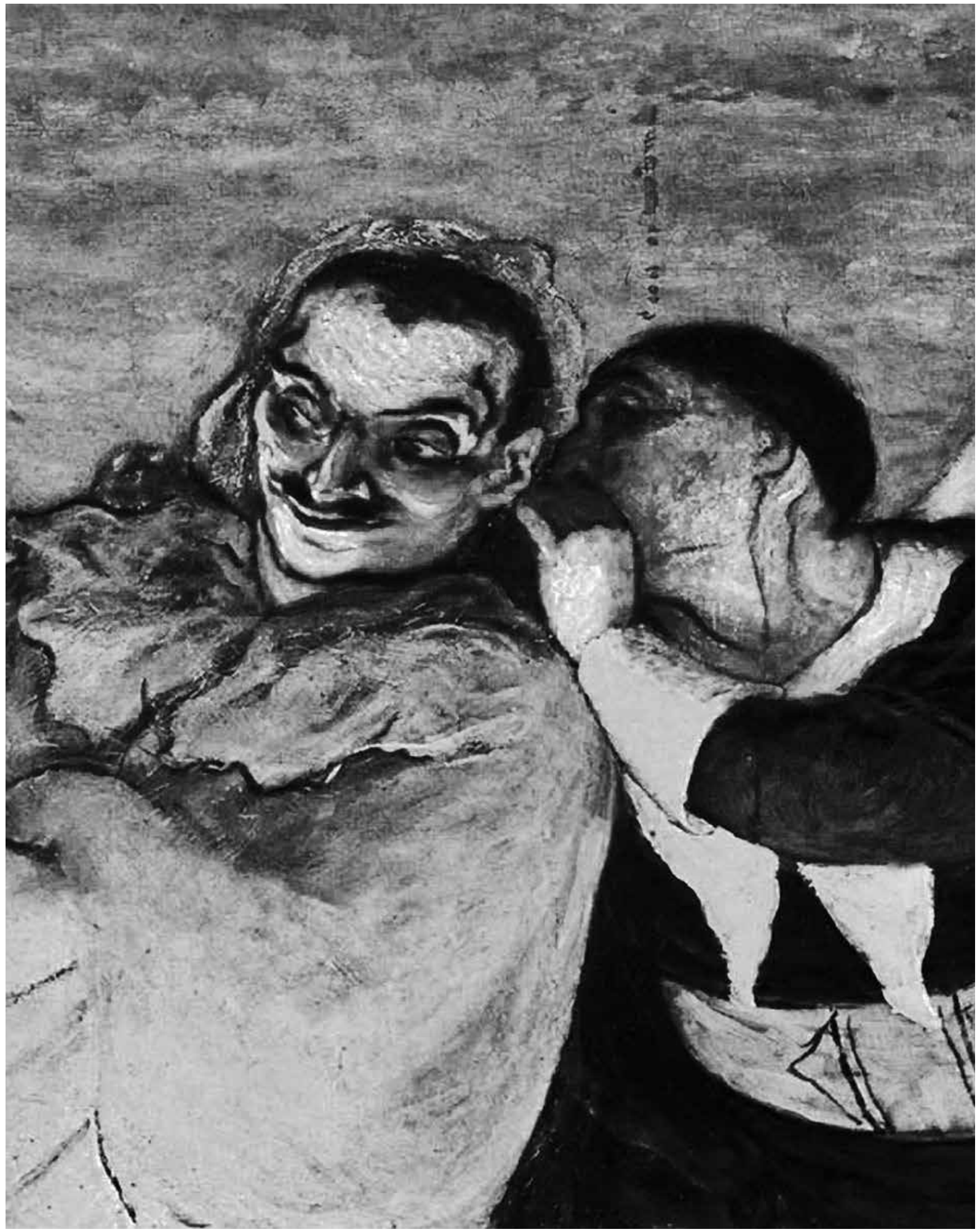




\section{O corpo continua a monte e a assombrar': Um tributo a Georg Büchner}

ANABELA MENDES

Anabela Mendes é germanista e professora no Departamento de Estudos Germanísticos da Faculdade de Letras da Universidade de Lisboa. É investigadora e conferencista em Literatura de Expressão Alemã, Cultura Alemã, Estética e Filosofia da Arte, Ciência e Arte, Teoria e Estética do Teatro, Sociologia das Artes do Espectáculo, Literatura Portuguesa, Literatura e Ciência e Literatura de Viagens. Recentemente concebeu e coordenou um projecto internacional e transdisciplinar dedicado a «Viagens de Longo Curso: Roteiros e mapeações».

Will there be in the work of Büchner such a character that so well corresponds to the conceptual structure where human imperfectibility establishes connection with a feeling of irreducible strangeness, here associated with the idea of Nature-God, as Woyzeck? What affects us concerning this character? Indeed what matters is the direct effect of the presence of nature as a misfit in the human domain, while we perceive that there is something we can never know what really is, although it touches us immeasurably. Woyzeck stirs us into his paradoxical behavior at various levels: he wants to be a good man and no longer is a good man; he feels in himself a strange disease that hallucinates and disturbs him; and because he wishes to become a good man, he does not realize that what is happening to him is a deviance in his good nature.

WOYZECK / NATURE / HUMANITY / AFFECTION / DISEASE

Não há quem não sinta, a certo momento, que a porção ou a forma de existência que lhe coube é demasiado pesada para as forças que tem. JOSÉ TOLENTINO MENDONÇA

ENTRE PORTAS

Despedimo-nos todos os dias um pouco da vida que vivemos, reconfortados porque a soubemos apreciar, inquietos e perturbados por tudo aquilo que não conseguimos resolver e nos assombra.

Quando exactamente esse perturbador tudo aquilo (o que provoca e é alvo de emoções e sentimentos mas também está no cerne das 
acções) não deixa por isso de ser vida e como tal em nós se manifesta nas suas mais significativas representações, formas e facetas, apercebemo-nos com agudeza da nossa insuficiência e dos espaços em branco que nos habitam. O tudo aquilo alcança a categoria de inominável mesmo que sejamos capazes de o fazer progredir em direcção a uma metamorfose em nós. No tudo aquilo existe e perdura um processo de diabolização (em nós conflito e exercício a favor da libertação) que se nos torna pouco a pouco familiar, nutrindo-se de uma energia transbordante que nos submerge.

Começaria por afirmar que dificilmente seremos capazes de oferecer a tudo aquilo que nos perturba num presente-acontecente, também alargado em direcção ao outro, um cristalino e imediato acolhimento. Este acolhimento quer dizer capacidade de compreensão e integração daquilo que nos emociona e onde descobrimos prazer e alegria, dor e tristeza, ou até que nos torna alvo de estados de espírito e de corpo que nos deixam muitas vezes a sensação de que perdemos o pé da realidade, qualquer que ela possa ser, correndo o risco de nos desfigurarmos, de nos contrariarmos, de nos contradizermos.

Perder o pé da realidade, das muitas realidades que nos constroem, é um movimento paradoxal entre o querer e o não querer, entre o ser capaz e o não ser capaz que pode emudecer em nós a relação com as coisas, aquilo que nos afecta, e a operação própria do entendimento. Estamos sempre a construir faróis que consigam iluminar os obstáculos a que queremos resistir ou que desejamos contornar, esperançosos de que aquilo que se nos atravessa no caminho transporte consigo uma energia, que fatalmente com outra se depara, e assim por diante. No entanto, sujeitos que somos a tantos embates e ao cortejo das suas variações, desencorajamo-nos na coragem, experimentamos os contornos de faróis-penumbra quando a luz nos encadeia, estrebuchamos no exacto momento em que nos estamos a reinventar pela busca $\mathrm{e}$ manutenção de uma identidade expressiva própria.

Verificamos, assim, que grosso modo não só se nos escapa muitas vezes a ideia e a consistência dos nossos limites e de todos os seus contornos, como, ao sermos impulsionados para irmos além das nossas reais possibilidades (faz parte da nossa natureza e da sobrevida), nos podemos pôr do lado do problema e não da solução.

As tonalidades e os matizes do nosso comportamento enquanto espécie, mas também quando olhamos para nós como indivíduos, 
nem sempre nos fornecem a consciência de que o universal coincide com o singular, isto é, não se esconde atrás daquilo que, embora particular, contém a inseparável condição da sua natureza. É por isso que sofrermos da incapacidade de nos despirmos de um corpo assombrado pode parecer uma questão insolúvel, quando comparado com o desejo de almejarmos preservar como se fosse para sempre aquilo que em nós foi luz e bênção.

Enredamo-nos num sentimento perverso que nos alucina, demasiadamente envolvidos que estamos em tecer resposta sobre pergunta e sem percebermos que a aprendizagem chega depois.

O que na vida nos perturba, seja por bem ou por mal, ou até sem que uma fronteira definida possa ser gizada entre essas duas instâncias, acontece porque tomamos consciência quase sempre tardia de que continua a haver qualquer coisa que nos escapa e que jamais a alcançaremos como seria nosso objectivo. Muitas vezes não é no que nos escapa e que perseguimos de forma obstinada e ruminadora que encontramos aquilo que nos pode devolver um novo engendramento. Quando essa parcela, que em nós define sequências de um trajecto de vida e nos constrói como identidade, nos perturba e também se nos escapa, torna evidente essa sensação de incompletude e impotência que nos impede de apagarmos ou recuperarmos integralmente aquilo que antes experimentámos. Caminharmos sobre miragem do vivido é a nossa condição e mesmo assim não desistimos de construir a partir de memórias e restos, às vezes com tão singulares objectos como uma pedra, uma concha, uma folha de árvore, tudo o que ainda nos faz falta e em nós estremece. Eis como eu sinto que funciona a nossa condição humana, precária, aquela que nos dói mas também pode consigo transportar formas de pacificação e alívio.

Neste contexto, o universo de Woyzeck, de Georg Büchner, também tantas vezes o nosso próprio universo, reflecte e sublinha o processo acima descrito. Esse sublinhado ocorre porque o trajecto de Woyzeck é o de um corpo a monte, um corpo desvalorizado e desprezado, um corpo que até o próprio Woyzeck sente que lhe escapa. É do viver em tal assombração que se fará discurso.

\section{A CÉU ABERTO}

Enquanto estudante, Georg Büchner estabelece com o pensamento do filósofo Espinosa uma espécie de pacto intermitente de convivência e diálogo que haveria de o acompanhar até à sua 
prematura morte. Em escritos tão distintos como o fragmento Traum eines Arcadiers (Sonho de Um Árcade), produzido no semestre de Inverno de 1829-30, e a Probevorlesung über die Schädelnerven (Lição Probatória sobre os Nervos Cranianos), apresentada como prova de agregação na Universidade de Zurique, a 5 de Novembro de 1836, é possível encontrarmos, ainda que de modos diversos, os fundamentos de uma espécie de manifesto filosófico concentrado em dois princípios que orientaram o livre-pensador Büchner: a filosofia tem de se ocupar exclusivamente das «coisas humanas»; a filosofia tem de utilizar uma «linguagem humana» (Büchner, 2012: 353). É justamente num registo eufórico, despretensioso e entusiasmado que, em carta ao amigo August Stoeber, datada de 9 de Dezembro de 1833, e escrita de Darmstadt, Büchner se confessa disponível para agarrar qualquer coisa que lhe está sempre a escapar e que é a filosofia:

atiro-me com toda a força à filosofia, a linguagem elaborada é abominável, acho que também se deveriam encontrar expressões humanas para o que é humano; mas isso não me incomoda, rio-me da minha loucura e acho que, no fundo, tudo não passa de um quebrar de nozes chochas.

(Poshmann, 1999: 376)

Significa então que, neste período que antecede a escrita da sua produção dramática, Büchner reconhece na filosofia o objecto do seu interesse. Não é leviano o modo como a pretende integrar na sua necessidade interna de criação. De facto só um louco, um louco muito lúcido, se poderia abalançar a transformar o novo em antigo, i. e., ser intérprete de uma filosofia - a de Espinosa em primeiro lugar mas também a de Descartes - a partir do seu método. Nesse sentido, quanto mais «nozes chochas» for capaz de reduzir a pó, mais satisfatória poderá ser a produção e articulação de ideias, termos e expressões conceptuais dotados de autonomia no seio da sua escrita. A isto se chama estabelecer uma íntima relação por afinidade.

Acresce dizer que, mesmo num texto de âmbito especulativo, como é o caso do juvenil ensaio Sonho de Um Árcade, nos sentimos acompanhados pela expressão de uma consciência e de um espírito crítico que caracterizam sintomaticamente a atitude büchneriana no que diz respeito à relação entre o ser humano e a Natureza. Já nessa altura o tom e a expressividade do seu pensamento não 
escondem a preocupação social e política que o inspira. Na óptica do autor, esse nexo que junta humano e Natureza continha então impreterivelmente os filtros de classe, educação e cultura.

A natureza e os seus fenómenos não são para ele uma finalidade em si e não interrompem a compreensão coabitada entre corpo e espírito. Por um lado, constatamos que Büchner se manifesta com fervor confesso e grande anseio objectivo sobre a ideia de que os «eternos fenómenos da natureza» provêm de um «princípio primordial, uma essência de tudo o que existe» e que, ao mesmo tempo, essa ideia cria uma insuspeita, talvez singular, identificação desse «princípio primordial»» ${ }^{2}$, inexplicado no texto de Büchner, com um horizonte em que Deus, os homens e as coisas do mundo e do além-mundo mantêm convivência íntima através e por meio da Natureza. Este é porventura um princípio que encontra eco na Ética (1677) de Espinosa (Parte I) e que perspectiva o preenchimento de sentido entre o que o filósofo defendia - cada coisa que existe é um modo, uma manifestação e prolongamento de Deus na própria matéria ${ }^{3}$ - e o que o dramaturgo-cientista e insurrecto batalhador pelos direitos dos desfavorecidos pensava e fazia no seu tempo. Büchner não se cansou de interrogar e anotar, nos últimos anos de vida, essa primeira parte da obra maior de Espinosa. O trabalho permaneceu fragmentário e sabemos hoje que a par do estudo directo do texto espinosano foram consultadas fontes secundárias, embora delas não exista registo directo no comentário produzido por Büchner. ${ }^{4}$

Sabemos ainda que é nos seus desdobramentos dramáticonarrativos, Lenz, A Morte de Danton, Woyzeck, Leôncio e Lena, os mais conhecidos de leitores e espectadores, que permanecem

Transcreve-se e traduz-se aqui a correspondente passagem do referido escrito do jovem Büchner: «Der rohe Mensch sieht Wunder in den ewigen Phänomenen der Natur, er sieht aber auch Wunder in außergewöhnlichen Fällen des Alltaglebens, für beide schafft er sich seine Götter, der Gebildete sieht in den Wundern erstrer Art nur die Wirkungen der unerforschten, unbegriffnen Naturkräfte, aber auch sie sind ihm Wunder, solange das blöde Auge des Sterblichen nicht hinter den Vorhang blicken kann, der das Geistige vom Körperlichen scheidet, auch sie weisen ihn zurück auf ein Urprinzip, ein<en> Inbegriff alles Bestehenden auf die Natur.» [O homem rude vê milagres no eterno fenómeno da Natureza, mas ele também vê milagres em casos extraordinários da vida quotidiana, em ambos os casos ele cria os seus deuses; o homem culto vê nos milagres do primeiro tipo apenas os efeitos das forças naturais inexploradas, incompreendidas, mas também elas são, para ele, milagres. Enquanto o olho estúpido dos mortais não conseguir olhar para lá da cortina que separa o espiritual do corpóreo, também estas o remetem para um princípio primordial, uma essência de tudo o que existe na Natureza.] (Poschmann, 1999: 29) modos e as manifestações da essência divina: o Mundo. A natureza naturante, isto é, Deus, prolonga-se na matéria como modo de manifestação de Deus; este basta-se a si mesmo no processo de automanifestação contínua - Natureza Criadora. 
os vestígios de uma Natureza-Deus implicada não na imortalidade, não no intangível nem no inatingível, mas exactamente naquilo que de mais terreno e terrível acontece a cada um no seu todo e que é perder-se de si. O mistério da vida bem vivida parece em Büchner estar omisso como um vínculo secreto entre formas ocultas e formas visíveis. A compreensão de todos os sinais que engendram a sua relação com aquilo que acontece e passa, o horizonte da experiência, e que procuram defender o melhor dos mundos para o ser humano, esbarram infalivelmente com a dor, a doença, o desconcerto, a morte. Todos estes indícios se espelham no corpo e na mente dos seus protagonistas. Todos estes indícios são fonte perturbadora das leituras e interpretações que dedicamos à sua obra.

Onde se situa então neste quadro conceptual a incandescência produzida por Espinosa em Büchner? Como poderemos explicar a perplexidade da existência de uma Natureza-Deus que somos capazes de compreender e que até nos pode comover, se a nossa imperfeição se sobrepõe a tudo isto como uma evidência irrefutável?

\section{A VERDADE DO CORAÇÃO}

Haverá na obra de Büchner personagem que tão bem corresponda ao quadro em que a imperfectibilidade humana estabelece nexo com um sentimento de estranheza irredutível, aqui associado à ideia de Natureza-Deus, como Woyzeck? Nele o que nos afecta é o efeito directo da presença da natureza como desajuste no domínio humano, ao mesmo tempo que intuímos a existência de qualquer coisa que jamais poderemos saber o que verdadeiramente é e que nos toca de forma incomensurável.

Woyzeck agita-nos no seu comportamento paradoxal a vários níveis: quer ser um bom homem e deixa de ser um homem bom; sente em si uma doença estranha que o alucina e perturba, e porque quer ser um homem bom, não percebe que o que lhe está a acontecer é um desvio na sua boa natureza. Ao querer fazer cumprir em si «o milagre, o princípio primordial de tudo o que existe na natureza» (Poschmann, 1999: 29), tal como a isso aludia Büchner em Sonho de Um Árcade, Woyzeck parece afeiçoar-se de modo muito íntimo àquilo que está sempre a perder e que é irrecuperável: o seu corpo, a sua identidade. Woyzeck transforma-se numa adversidade da natureza porque aquilo que ainda nele é «experiência e sujeito» (Schiller, 2003: $\$ 32$ ), 
e que o torna idêntico a si próprio nas respectivas formas de regulação da vida (procurar sustento, constituir família, mas também ser feliz), o põe também em risco, arrastando consigo a denegação desses propósitos.

Deste ponto de vista, e sem que se ponha em causa uma capacidade comum à espécie humana e a outras espécies animais - a de criar afecto e sentimento ${ }^{5}$-, apercebemo-nos de que esta aptidão está desregulada na natureza do protagonista da peça homónima de Büchner. Woyzeck parece não possuir condições físicas, mentais e emocionais para se espelhar como existência na essência espinosana. A Woyzeck, não são dadas condições para que o trânsito entre «experiência e sujeito» e «ideia e objecto», na óptica de Schiller (ensaio Sobre a Poesia Ingénua e Sentimental, $\$ 32)$, possa realizar-se sem sobressalto.

Woyzeck continua a ser imanência, na perspectiva de tudo o que abrange o horizonte da sua existência e é fonte de normas e valores, mas o que lhe é adverso é o reconhecimento dessa realidade com a qual não é capaz de conviver e que não o conduz nem à libertação nem à emancipação.

Libertação e emancipação significariam então reforço de identidade na procura de felicidade no seu sentimento de humanidade. Significariam ainda um reencontro com o idêntico em si e com a inteira e infinita Natureza como projecção e como parte que a integra. Significariam finalmente o reconhecimento de que «cada coisa que existe é um modo, uma manifestação e prolongamento de Deus na própria matéria».

Woyzeck não se liberta nem se emancipa. Woyzeck é. É-o exclusivamente pela necessidade da sua natureza. Para Espinosa, para Büchner, Woyzeck tem a liberdade que a sua natureza lhe permite ter e nada mais. É na sua natureza que ele se revê e nela vai tentando ultrapassar as adversidades que o preenchem e ocupam. Woyzeck exerce a seu modo a capacidade de livre-arbítrio. Escolhe mal, diríamos nós, ou a sua ideia de juízo livre não tem equivalência nos nossos códigos e princípios éticos?

Woyzeck ocupa na peça de Büchner o lugar de um traço, de uma fronteira entre isto e aquilo, que se está sempre a esculpir 
e a apagar ora na terra, ora no céu, ora em águas rumorejantes, ora a deixar-se atrair por incauto fogo. O seu lugar está sempre a acontecer entre nós e devasta-nos porque não somos capazes de o acolher com o afecto amoroso de que ele precisa. Somos impiedosos no nosso juízo crítico, porque matar não é bom, e até nos esquecemos de que ele pode representar muito daquilo que nos escapa e não conseguimos resolver. Woyzeck é o nosso perdedor inconformado, sem direito a escolha nem a afirmação, postado numa natureza adversa, que talvez nem tenha plena consciência do que quer dizer «sentir de forma natural», do que quer dizer «ser natural». Como dizia Schiller: «O nosso sentimento pela natureza é igual ao que o doente sente pela saúde» (2003: 31). A assombração de Woyzeck é a nossa doença.

\section{REFERÊNCIAS BIBLIOGRÁFICAS}

BÜCHNER, Georg (2012), Sämtliche Werke und Briefe, ed. Ariane Martin, Estugarda, Reclam.

DAmÁsıo, António (2010), O Livro da Consciência: A Construção do Cérebro Consciente, Lisboa, Temas e Debates/Círculo de Leitores.

ESPINOSA, Bento (1992), Ética, Lisboa, Relógio D’Água.

MENDES, Anabela (2004), «Büchner em diálogo com Espinosa», in Ana Fernandes (org.), Visão de Portugal por Estrangeiros, $3 \cdot^{\mathrm{a}}$ Jornada, Viseu, Centro de Literatura e Cultura Portuguesa e Brasileira, pp. 69-84.

MENDONÇA, José Tolentino (2014), Trocar de Mãos, in «que coisa são as nuvens», Expresso, Revista, 23 de Agosto, p. 1.

poschmann, Henri (ed.) (1999), Georg Büchner, Schriften, Briefe, Dokumente, Bd. II, Frankfurt am Main, Deutsche Klassiker Verlag.

SCHILLE R, Friedrich (2003), Sobre a Poesia Ingénua e Sentimental [Über nä̈ve und sentimentalische Dichtung], tradução, introdução, comentário e glossário de Teresa Rodrigues Cadete, Lisboa, Estudos Gerais - Série Universitária Clássicos de Filosofia, Imprensa Nacional-Casa da Moeda. 